\title{
Succesful oral desensitization in a teenage boy with severe cow's milk allergy
}

\author{
ZU Tamay ${ }^{1 *}$, B Aliyev², F Dilek ${ }^{3}$, N Guler ${ }^{1}$ \\ From Food Allergy and Anaphylaxis Meeting (FAAM 2013) \\ Nice, France. 7-9 February 2013
}

\section{Background}

Severe cow's milk allergy can cause life-threatening reactions. Specific oral desensitization (SOD) can be effective and improve quality of life of the children and their families.

\section{Case report}

A fourteen-year old boy was referred to our clinic for follow-up with the diagnosis of cow's milk allergy. At 3 months of age, he had immediate rash around his mouth and vomiting when he was first introduced with infant formula. Since then, he was on a milk restriction diet. He had three anaphylactic reactions needing emergency visit, and epinephrine injections. His last anaphylactic reaction was 2 months before the referral. His serum specific IgE was $49.8 \mathrm{kU} / \mathrm{L}$.

\section{Methods}

Specific oral desensitization (SOD) was performed according to protocol developed by Longo et al. The protocol consisted of 2 phases; the first phase was applied at hospital and the second phase was continued at home. The first phase was completed when $20 \mathrm{ml}$ pure cow's milk was achieved. The second phase was applied at home by the parents with gradual increase in milk dose.

\section{Results}

During hospital admission he had two mild reactios needing antihistamines and nebulised adrenaline. He is still at the second phase of the protocol now. He can tolerate $200 \mathrm{ml}$ of cow's milk now; he can eat yoghurt instead of milk (half of daily amount of milk).

\section{Conclusion}

SOD can be effective and life-saving treatment especially for children with severe cow's milk allergy to overcome life-threatening episodes of accidental ingestions.

\section{Disclosure of interest}

None declared.

\section{Author details}

'Department of Pediatric Allergy and Immunology, Istanbul Medical Faculty, Istanbul, Turkey. ${ }^{2}$ Department of Pediatrics, Istanbul Medical Faculty, Istanbul, Turkey. ${ }^{3}$ Department of Pediatrics, Ethica Incirli, Istanbul, Turkey.

Published: 25 July 2013

\section{References}

1. Barbi e, Longo G, Berti I, Matarazzo L, Rubert L, Saccari A, Lenisa I, Ronfani L, Radillo O, Ventura A: Adverse effects during specific oral tolerance induction: in home phase. Allergol Immunopathol (Madr) 2012, 40(1):41-50.

2. Barbi E, Longo G, Berti I, Neri E, Saccari A, Rubert L, Matarazzo L, Montico M, Ventura $A$ : Adverse effects during specific oral tolerance induction: inhospital "rush" phase. Eur Ann Allergy Clin Immunol 2012, 44(1):18-25.

3. Longo G, Barbi E, Berti I, Meneghetti R, Ronfani L, Pittalis A, Ventura A: Specificoral tolerance induction in children with very severe cow's milkinduced reactions. J Allergy Clin Immunol 2008, 121(2):343-7.

doi:10.1186/2045-7022-3-S3-P122

Cite this article as: Tamay et al: Succesful oral desensitization in a teenage boy with severe cow's milk allergy. Clinical and Translational Allergy 2013 3(Suppl 3):P122. 